\title{
Review Article \\ Certain Aspects of Silver and Silver Nanoparticles in Wound Care: A Minireview
}

\author{
Marek Konop, ${ }^{1,2}$ Tatsiana Damps, ${ }^{1,2}$ Aleksandra Misicka, ${ }^{1}$ and Lidia Rudnicka ${ }^{1,2}$ \\ ${ }^{1}$ Department of Neuropeptides, Mossakowski Medical Research Centre, Polish Academy of Science, \\ 5 Pawinskiego Street, 02-106 Warsaw, Poland \\ ${ }^{2}$ Department of Dermatology, Medical University of Warsaw, 82A Koszykowa Street, 02-008 Warsaw, Poland \\ Correspondence should be addressed to Marek Konop; marek.konop@wp.pl
}

Received 2 November 2015; Accepted 11 January 2016

Academic Editor: Piersandro Pallavicini

Copyright (C) 2016 Marek Konop et al. This is an open access article distributed under the Creative Commons Attribution License, which permits unrestricted use, distribution, and reproduction in any medium, provided the original work is properly cited.

\begin{abstract}
Resistance to antimicrobial agents by pathogenic bacteria has emerged in recent years and is a major health problem. In this context silver and silver nanoparticles (AgNP) have been known to have inhibitory and bactericidal effects and was used throughout history for treatment of skin ulcer, bone fracture, and supporting wound healing. In all of these applications prevention and treatment of bacterial colonized/infected wounds are critical. In this context silver and its derivatives play an important role in health care. Silver is widely used in clinical practice in the form of silver nitrate and/or silver sulfadiazine. In the last few years silver nanoparticles entered into clinical practice as both antimicrobial and antifungal agents. In addition, nanosilver is used in coating medical devices (catheters) and as component of wound dressings. In this paper we present summarized information about silver and nanoparticles made of silver in the context of their useful properties, especially antibacterial ones, being of a great interest for researchers and clinicians.
\end{abstract}

\section{Introduction}

The emergence of bacterial resistance to antimicrobial drugs has become a serious problem in health care due to abuse of commonly available antibiotics. It is a result from their evolutionary processes occurring in the course of an antibiotic treatment. The resistant bacteria survive medical treatment and pass this trait to future generations $[1,2]$.

In this context silver nanotechnology plays an important role since silver (either metallic $\mathrm{Ag}^{0}$ or that existing in ion form of $\mathrm{Ag}^{+}$) is known to be a broad spectrum antibiotic with antiseptic, antimicrobial, anti-inflammatory, and prohealing properties. Thus, silver nanoparticles or structural materials play a critical role as an important class of materials that have found application mainly in health industry as antibacterial agents (wound dressing, medical equipment), but also in cosmetic and food industry and textile coatings and in a number of various environmental applications [3-6].

\section{Short History of Silver}

For thousands of years silver has been used as a healing agent by civilizations throughout the world. Silver is a silvery metal element positioned 47 th in the periodic table. Pure silver exhibits the highest electrical and thermal conductivity and at the same time has a lowest contact resistance $[7,8]$. Silver and its derivatives have been long used as antimicrobial agents. The first report of the use of silver comes from the year $3500 \mathrm{BC}$, where in predynastic Egypt silver was used as coins. Regarding its therapeutic properties silver is known for more than 1000 years BC. Water was stored in silver or copper vessels and exposed to light or filtered, unfit for human consumption $[6,9$, 10]. Hippocrates-father of modern medicine-also used silver; he believed that silver powder has beneficial therapeutic effect and antidisease properties. Silver has been used in the treatment of various maladies including ulcers $[6,8,9]$. 
The first report about silver nitrate comes from pharmacopeia published in Rome in $69 \mathrm{BC}$, first information about medical use of silver nitrate began from Gabor (702-705 AD). In 1520 Paracelsus has been using silver and silver nitrate for treatment of wounds. Ambrosie Pare used silver clips in facial reconstruction [11, 12]. Between the 1700s and 1800s silver nitrate was used to treat venereal infections, leg ulcer, and acne. It was also used in the treatment of patients with epilepsy [7, 13-15].

The antibacterial properties of silver and its salts were recognized after bacterial discovery. Silver nitrate has entered into clinical practice and has been applied in the treatment of skin ulcer and bone fracture supporting wound healing. In 1884 German obstetrician-Crede-applied $1 \% \mathrm{AgNO}_{3}$ in the form of eye drops for newborns to prevent gonorrheal infection. The first Chief of Surgery at Johns Hopkins Hospital doctor William Halsted advocates for using silver wire sutures in surgery for hernia. He also founded silver foil as an effective method of controlling postoperative infections in surgical wounds [11, 15-17]. Roe used a colloidal silver in treatment of infected corneal ulcers [18].

In the last twenty years of the 20th material containing silver was effectively used for water purification [19-21], wound dressings for the promotion of healing [22, 23], the prevention and treatment of infection [23], dental hygiene [24], eye conditions [25], and other infectious complications. In the 21st century, medicinal use of silver extended beyond the use in the treatment of burns or wound dressings. Indeed, it started to be applied to hospitalized patients with infections of the urinary tract and catheter-related bloodstream infections [17].

\section{Mechanism of Antimicrobial Action}

The exact mechanism of action of silver on the microbes is still unknown. However the possible mechanism of action of metallic silver, silver ions, and silver nanoparticles has been suggested according to the morphological and structural changes found in the bacterial cells.

3.1. Mechanism of Action of Silver. Silver has a broad spectrum of activity against aerobic and anaerobic Grampositive and Gram-negative bacterial strains [26, 27]. Metallic/elemental silver is chemically inactive, poorly absorbed by mammalian or bacterial cells. To gain antibacterial properties, the ionization (in presence of body fluid or secretions) is highly required. After entry into the cell silver ion interacts with structural and enzymatic proteins [9, 26, 28, 29]. Then the insoluble compounds are formed, which are essential components of the enzymes responsible for transmembranous energy metabolism and electrolyte transport. In bacteria, $\mathrm{Ag}^{+}$interacts with nucleophilic amino acid residues in proteins. Silver rapidly interacts with sulfhydryl, amino, imidazole, phosphate, and carbonyl group present on membrane or enzyme proteins in microorganism. During interaction between silver ions and functional group hydrogen atoms are replaced by ionized silver, which as a result create S-Ag bonds $[9,30]$. Ionized silver blocks the respiratory chain at the level of appropriate respiratory enzymes: cytochrome oxidase and NADH-succinate-dehydrogenase $[31,32] . \mathrm{Ag}^{+}$ions are able to form complex with nucleic acid (DNA or RNA) block transcription, while those that bind to cell surface components interrupt bacterial respiration and adenosine triphosphate (ATP) synthesis.

Silver ions interact with membrane proteins and additionally block the respiratory chain. After penetration into the cell $\mathrm{Ag}^{+}$interacts with both DNA and proteins and finally induces production of reactive oxygen species (ROS) (see Figure 1, adapted from [33] with slight modifications).

3.2. Mechanism of Action of Silver Nanoparticles (AgNP). The silver nanoparticles show efficient antimicrobial properties compared to other silver compounds due to their large surface area. The extensive surface morphology provides better contact with microorganisms. AgNP interact with cell membrane and then penetrate inside the cell. Bacterial cell membrane contains proteins, which include sulfur. AgNP interact with these proteins, as well as with the phosphorus containing compounds, like DNA. Following entry into the bacterial cell it forms a low molecular weight region in the center of the bacteria to which the bacteria conglomerate, thus protecting the DNA from the silver ions. The AgNP interact with the respiratory chain and cell division finally leading to cell death $[2,30-32,34,35]$. This was found while applying AgNP on Gram-positive and Gram-negative bacteria, including highly multiresistant strains [36].

\section{Application of Silver in Medicine}

Silver products are used in medicine and clinical practice as expanding range of products. The most important application is undoubtedly as a biocide to prevent long-term infections' problem including burns, traumatic wounds, and diabetic ulcers. Additional applications include wound dressing, coating of catheters, and other devices implanted on or within the body. In clinical practice silver compounds in different forms and concentrations are still used.

4.1. Silver Sulfadiazine. The gold standard in the treatment of patient with topical burns is silver sulfadiazine (AgSD, see Figure 2) introduced for the treatment of burns in 1970 by Fox. It is used to prevent and treat infections of second- and third-degree burns. It is harmful to a wide variety of bacteria (Gram-positive cocci, S. aureus and Gram-negative bacilli, particularly $P$. aeruginosa) $[37,38]$.

Muangman et al. [39] compared the efficacy of $1 \%$ silver sulfadiazine versus Aquacel $^{\circledR} \mathrm{Ag}$ dressing in the treatment of second-degree burns. This prospective, randomized study included 70 patients divided into two equal groups according to the burn wound treatment. Group treated with Aquacel Ag has changed dressing every 3 days, whereas in a group treated with $1 \%$ silver sulfadiazine it was changed every day. This study showed that Aquacel Ag promoted time-to-wound healing decreased pain symptoms associated with the change of dressing and tended to lower the total treatments cost. The obtained results suggest that Aquacel Ag is an effective burn dressing in superficial second-degree burns. 


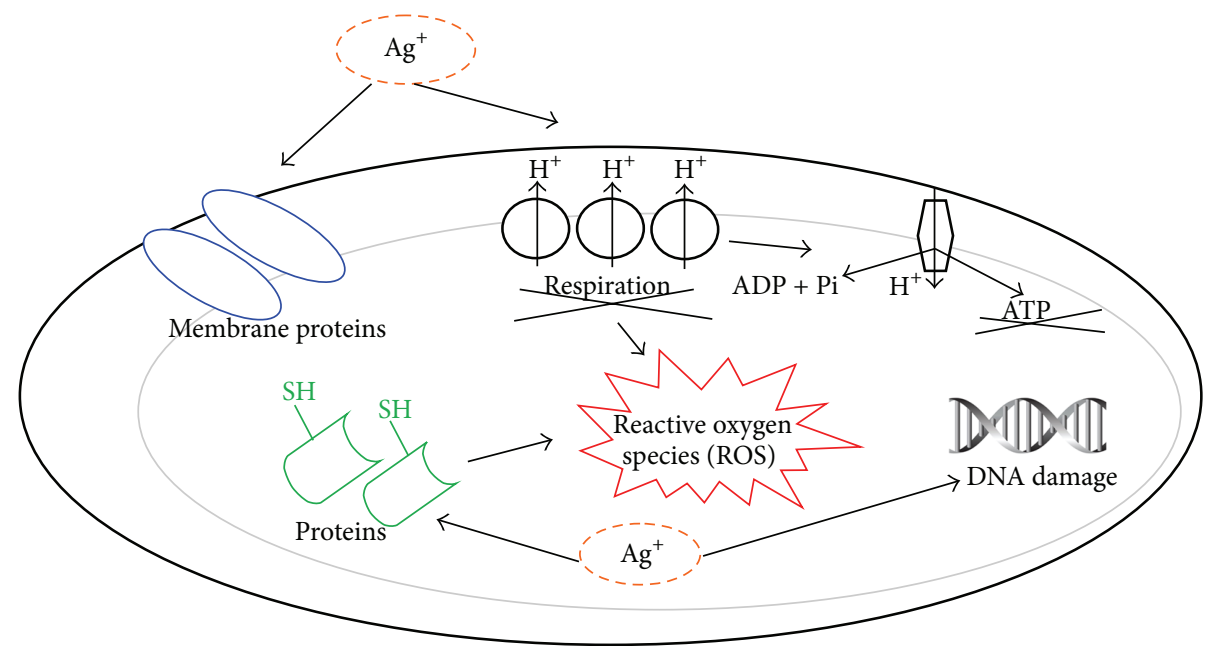

Figure 1: Antimicrobial effects of $\mathrm{Ag}^{+}$[33].<smiles>Nc1ccc(S(=O)(=O)Nc2ncccn2)cc1</smiles>

FIGURE 2: Structure of silver sulfadiazine.

The other group working on burn wounds and silver compounds applications was a team led by Opasanon et al. [38] who compared Askina Calgitrol $\mathrm{Ag}^{\circledast}$ with $1 \% \mathrm{AgSD}$ on the management of partial-thickness burn wounds. In this study 65 burnt patients were identified and randomized into two groups: one treated with $1 \%$ of AgSD (35 patients) and the second one (30 patients) with Askina Calgitrol Ag dressing. Askina Calgitrol Ag preparation is able to be left in situ for treatment of partial-thickness burn wounds up to 3-5 days. It provides an antimicrobial effectiveness while enhancing a moist wound environment leads to rapid granulation and reepithelialization of damaged tissue. The results obtained by this group suggested that burns heal significantly faster in Askina Calgitrol Ag group (7 days) compared with 14 days of the $1 \%$ AgSD-treated group.

Mabrouk et al. [40] compared moist occlusive dressing (Aquacel Ag, $n=20$ ) versus moist open dressing (MEBO, $n=20)$ in patients with partial-thickness facial burns. They reported that wound treated with Aquacel Ag heals faster (10.5 days) compared to MEBO treated (12.4 days). Frequency of changes, pain, and patient discomfort was less in the group with Aquacel Ag; also scar quality was improved in this group. In summary, most occlusive dressing, such as Aquacel Ag, significantly improves the management and healing rate of patients with partial-thickness facial burns and showed excellent results. Its efficacy in controlling infection, adherence to the wound, and acceleration of the time of healing was very high when compared to MEBO dressing.
4.2. Antibacterial Properties of Silver Nanoparticle. Sondi and Salopek-Sondi [2] reported the antimicrobial properties of AgNP in relation to the growth of E. coli (strain B) cultured on Luria-Bertani (LB) agar plates. The results obtained show that inhibition was dependent on AgNP concentration and initial number of cells used for the tests. Silver nanoparticles in concentration of $50-60 \mu \mathrm{g} \mathrm{cm}{ }^{3}$ caused $100 \%$ inhibition of bacterial growth. However, the concentration of $20 \mu \mathrm{g} \mathrm{cm}^{3}$ completely inhibited bacterial growth. Morones and coworkers [34] tested antibacterial activity of AgNP (size 1-100 nm) on different Gram-negative bacteria. They reported that antibacterial properties of AgNP against Gramnegative bacteria consist of three steps. In the first place, silver nanoparticles (average size 1-10 nm) attack bacterial cell membrane, which affects the change in their functions (e.g., permeability, respiration). After loss of containment, particles enter into the cell and cause further damage. Additionally AgNP release silver ions, which further enhance the bactericidal effect of nanoparticles.

In 2007, Kim et al. [41] tested antimicrobial activities of AgNP against yeast, E. coli, and S. aureus. These microorganisms were cultured on Muller Hinton agar (MHA) plates treated with different concentrations ( 0.2 to $33 \mathrm{nM}$ ) of AgNP. They reported that minimal inhibitory concentration (MIC) of AgNP for $E$. coli was $3.3 \mathrm{nM}$ whereas in relation to yeast it was equal to $6.6 \mathrm{nM}$. Interestingly, the growth-inhibitory effects of AgNP on S. aureus were observed in high concentration $(\mathrm{MIC}>33 \mathrm{nM})$.

Also Shrivastava et al. [42] examined antibacterial effects of AgNP on antibiotic-resistant and nonresistant strains of E. coli, ampicillin-resistant E. coli, and a nonresistant strain of $\mathrm{g}$ S. aureus. They also tested multidrug-resistant S. typhi. Cultures (106 colony forming units (CFU) of each strain per plate) were grown on LB agar plates containing Ag nanoparticles (concentration of $5,10,25$, and $30 \mu \mathrm{g} / \mathrm{mL}$, resp.). In plates with nonresistant $E$. coli the inhibitory effect of $60 \%$ and $90 \%$ was observed for plate supplementation with 5 and $10 \mu \mathrm{g} / \mathrm{mL}$ of AgNP, respectively. Complete inhibition of bacterial growth was observed when the $25 \mu \mathrm{g} / \mathrm{mL}$ AgNP 


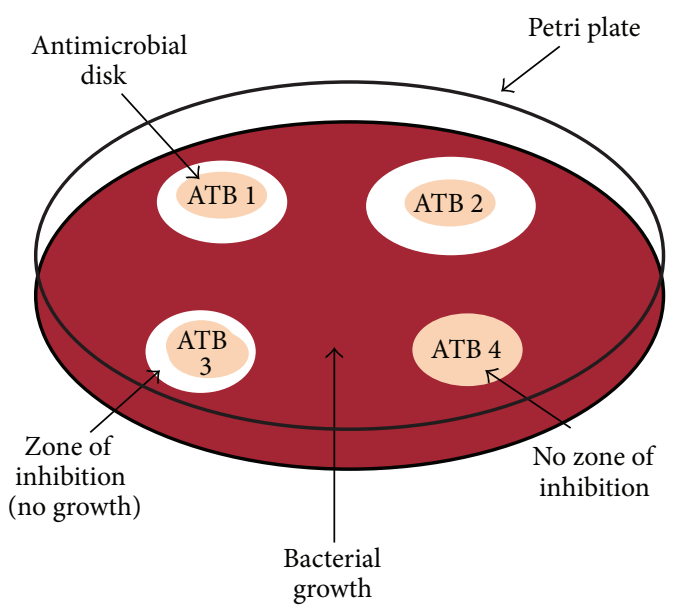

FIgURE 3: The diagram shows the idea of disk diffusion method (ATB 1: antibiotic 1, ATB 2: antibiotic 2, etc., created by author).

was used. In case of multidrug-resistant strains of $S$. typhi and ampicillin-resistant E. coli a 70-75\% inhibition in plates supplemented with $10 \mu \mathrm{g} / \mathrm{mL}$ of AgNP was noted. Whilst concentration of $25 \mu \mathrm{g} / \mathrm{mL}$ and greater completely inhibited microbial growth. Interestingly, none of the doses of nanoparticles had any effect on the growth of $S$. aureus. In summary, Gram-negative bacteria are more sensitive to the different doses of silver nanoparticles than Gram-positive bacteria.

4.3. Conjunction of $A g N P$ with Antibiotics. Disc diffusion method is a standard technique used in clinical microbiology laboratories for antibiotic susceptibility testing (AST) [43]. This assay is based on the diffusion of the antibiotic from the disc into agarose gel (see Figure 3). The concentration of the antibiotic is highest in the vicinity of the disc and decreases with the distance from the center. The measure of the sensitivity of tested strain is size of inhibition zone around the disk saturated with antibiotics [44].

Organisms more resistant to the drug are able to grow at a shorter distance from the disk. On the contrary, organisms less resistant withstand only lower concentrations and begin to grow at a somewhat greater distance from the disc [44].

Nowadays it is of great interest to combine silver nanoparticles with several various drugs, such as antibiotics, which is aimed at improving the treatment process. Iranian scientists under the leadership of Shahverdi [45] investigated the combination effect of AgNP with different antibiotics against $S$. aureus and E. coli using disc diffusion method. Results showed that antibacterial activities of penicillin $G$, amoxicillin, erythromycin, clindamycin, and vancomycin increased in presence of AgNP against both bacteria. They did not observe any effect when they tested Carbenicillin 100 , cephalexin 30 , cefixime 5 , gentamicin 10 , amikacin 30 , tetracycline 30 , cotrimoxazole 25 , nitrofurantoin 300 , and nalidixic acid 30 with addition of nanoparticles. In contrary, they observed highest enhancing effects of combined AgNP with vancomycin, amoxicillin, and penicillin G against $S$. aureus. Rajawat and Qureshi [46] tested AgNP in combination with ampicillin $(10 \mathrm{mcg})$ and gentamycin $(15 \mathrm{mcg})$ against S. typhi. The obtained results showed that the zone size for sample with ampicillin was larger than the zone size for gentamicin. In addition to this, Fayaz and coworkers [47] examined silver nanoparticles and their synergistic effect with antibiotics against S. typhi, E. coli, S. aureus, and M. luteus. In order to evaluate the synergistic effect of AgNP associated with an antibiotic (ampicillin, kanamycin, erythromycin, and chloramphenicol, concentration $10 \mu \mathrm{g} / \mathrm{disc}$ ) disc diffusion method was used. They reported that antibacterial activity of all used antibiotic increased in the presence of AgNP. Moreover, the highest enhancing effect was observed for combination of AgNP and ampicillin against tested strains.

Thomas et al. [48] tested the antibacterial potential of biosynthesized AgNP, standard antibiotics, and their conjugates against multidrug-resistant biofilm-forming coagulasenegative S. epidermidis strains $(73,145$, and 152) isolated from patients (pus, catheter tips, and blood samples). Other pathogenic bacteria, S. aureus (MTCC 87), V. cholerae (MTCC 3906), S. typhi, and S. paratyphi, were collected from the clinical laboratory. Disk diffusion method was used to evaluate the synergistic effect of antibiotics with biosynthesized AgNP against test strains on Mueller-Hinton agar plates. Standard antibiotic disks, fusidic acid $30 \mu \mathrm{g} / \mathrm{disk}$, gentamycin $10 \mu \mathrm{g} / \mathrm{disk}$, ciprofloxacin $30 \mu \mathrm{g} / \mathrm{disk}$, erythromycin $15 \mu \mathrm{g} /$ disk, penicillin $10 \mu \mathrm{g} /$ disk, chloramphenicol $50 \mu \mathrm{g} / \mathrm{disk}$, levofloxacin $5 \mu \mathrm{g} /$ disk, nalidixic acid $30 \mu \mathrm{g} / \mathrm{disk}$, and ampicillin $25 \mu \mathrm{g} / \mathrm{disc}$, were used. To determine the combined effects, each standard antibiotic disk was impregnated with freshly prepared AgNP (the final content of $10 \mu \mathrm{g}$ per disk). The received results showed remarkable antibacterial activity of AgNP against all test strains with the highest activity against S. epidermidis strains 145 and 152. In addition, the highest synergistic effect of AgNP was observed with chloramphenicol against $S$. typhi.

Naqvi et al. [49] studied AgNP and different antibiotics against multidrug-resistant bacteria (E. coli, P. aeruginosa, $E$. faecalis; S. aureus, M. luteus, A. baumannii, K. pneumoniae, and Bacillus spp.). A selection of five different antibiotics was made, that is, imipenem (carbapenem), trimethoprim (sulfonamide), gentamycin (aminoglycoside), vancomycin (glycopeptide), and ciprofloxacin (quinolone). Bacteria were grown on Mueller-Hinton agar plates, and the Kirby-Bauer disc diffusion method was applied. It was observed that the antibacterial activity of imipenem, gentamycin, vancomycin, and ciprofloxacin increased in the presence of AgNP.

4.4. Catheters Containing Silver. The medical devices should be made from materials which exhibit antimicrobial properties. In this context, silver nanoparticles have appropriate properties arising from their extremely large surface-tovolume ratio; also ionized silver shows resistance to oxidation and can be slowly released from medical equipment in active forms [50].

Central venous catheters (CVC) are extensively used in critical care unit for monitoring and therapy. After implantation into the human body, they can become colonized with variable microorganisms within $24 \mathrm{~h}$ from insertion, which can rapidly form biofilm. 
Roe et al. [51] tested antibacterial activity and evaluated the risk of systematic toxicity of novel catheters impregnated with AgNP. A prolonged release of silver from catheters (determined in vitro and in vivo) over a period of 10 days has been reported. Antibacterial properties of examined catheters were tested on E. coli, Enterococcus, S. aureus, coagulasenegative staphylococci: $P$. aeruginosa, and $C$. albicans. Silver catheters exhibit significant antimicrobial activity in vitro and prevent biofilms formation against all tested microorganism. In summary, the tested catheters occurred to be nontoxic and may be useful in preventing infectious complications in patients with indwelling catheters.

Khare et al. [52] examined the effect of a silver zeoliteimpregnated catheter on catheter-related colonization and infection in adult patients in intensive care units. The study was conducted at three acute hospitals and within the period of 14 months, 122 silver-impregnated and 124 nonimpregnated CVC were used. They found that overall rate of colonization was significantly lower in patients with silver zeolite-impregnated catheter (58\%) compared to the control group (78\%). Apart from this, a lower rate of tip colonization (34\%) by negative staphylococci was observed in the silver zeolite-impregnated CVC as compared to nonimpregnated CVC (47\%).

Stevens and coworkers [53] reported a development of a new bifunctional coating which can be applied to make CVC surfaces with dual antimicrobial and antithrombogenic activity. The new coating proposed by this group consists of a mixture of copolymers (N-vinylpyrrolidone (NVP) and nbutyl methacrylate (BMA)) containing AgNP and sodium heparin. The results of this research were that AgNP strongly inhibit adhesion of reference and clinical isolated strains of $S$. aureus on CVC. Additionally, used heparin made the catheter surface nonthrombogenic and contributed synergistically with their biocidal activity of AgNP.

A significant part of hospital-acquired infections is urinary tract infections (UTI). The most important predisposing factor for urinary tract infection is urinary catheter left in urinary system. Akiyama and Okamoto [54] were the first who reported in 1979 the use of silver-coated urinary catheters in 102 catheterized patients. In patients with silver catheters they did not observed bacterial infection (bacteriuria as symptoms of urethritis). In contrast, in control group (20 patients) having the conventional catheters, a bacteriuria within 4 days of catheterization was noted.

Karchmer and colleagues [55], who conducted a 12month randomized crossover trial, compared rates of nosocomial catheter-associated UTI in patients with silver-coated and uncoated catheters. They observed that the relative risk of infection per 1000 patient-days was 0.79 (95\% confidence interval, 0.63-0.99; $P=0.4$ ) for study wards randomized to silver-coated catheters compared with patients who got uncoated catheters. In conclusion, the risk of infection was reduced by $21 \%$ in the wards where the silver catheters were used.

4.5. Wound Dressing Containing Silver. An ideal wound dressing should maintain a moist environment at the wound side, allow for gaseous exchange, act as a barrier to microorganisms, and remove excess exudates. It should also be nontoxic as well as nonallergenic for patients tissue. Furthermore, the ideal dressing should be nonadherent and can be easily removed without trauma. It should be made from a readily available biomaterial that requires minimal processing, possesses antimicrobial properties, and promotes wound healing $[56,57]$. Natural biomaterials (collagen, gelatin, fibroin, and keratin) and their derivatives can be used in clinical practice as potential biodegradable wound dressing. Dressings containing silver are the basis for treatment of burns, acute and chronic wounds.

Jeong and coworkers [58] examined influence of silk fibroin (SF) nanofibrous matrices containing silver sulfadiazine in wound healing. They tested silver sulfadiazinemodified SF (in concentrations $0.1,0.5$, and $1.0 \mathrm{wt} \%$ ) in vitro on two cell lines: normal human epidermal keratinocytes (NHEK) and normal human epidermal fibroblasts (NHEF). In vitro results showed that number of NHEK and NHEF attached to examined nanofibers containing SSD decreased when the concentration of SSD increased. The number of attached NHEF cells was lower than attached NHEK cells. In addition, silk fibroin nanofibrous containing SSD were tested in vivo; rat wound model was used to determine the wound healing effect of SF nanofibers as compared to commercially available wound dressing Acticoat ${ }^{\mathrm{TM}}$. In vivo studies indicated that SF matrix with $1.0 \mathrm{wt} \%$ SSD produced faster wound healing than Acticoat.

Finley et al. [59] examined silver dressings in normal and diabetic wounds. They used animal model of full thickness wounds (5 $\mathrm{mm}$ in diameter) in normal (wild type C57BL/6) and diabetic (BKS.Cg- $\mathrm{m}+/+\mathrm{Leprdb} / \mathrm{J})$ mice. Wounds were created on the back and treated with silver or gauze dressing. They observed reduction of bioburden in silver-treated wounds in wild type mice. Moreover, they observed improved healing in diabetic mice where wounds were treated with silver dressing. However, the bioburden effect was not observed in diabetic wound treated with silver dressing.

Lin and coworkers [60] investigated the potential of KoCarbonAg ${ }^{\oplus}$, Aquacel Ag, and Acticoat 7 in reducing bacterial survival and promoting wound healing. In vitro results showed that the silver-containing dressings prevented bacterial ( $P$. aeruginosa) growth in wounds by blocking the entry of external bacteria and by retaining the bacteria in the dressing. They used a rat model to compare the healing efficiency of the dressings and investigate the quantity of collagen synthesis during healing process. In vivo studies showed that KoCarbonAg and Aquacel Ag have better capacity to block, retain, and kill microbes than Acticoat 7 and gauze. The in vivo studies indicated that reduction in bacterial burden accelerated healing and wound covered by silver dressing showed better healing that gauze treated wound. Moreover, applied KoCarbonAg dressing accelerates wound healing by promoting collagen synthesis and arrangement.

In another study Lin et al. [61] investigated commercially available silver dressing (Acticoat 7, Silverlon, and Actisorb Silver 220) and silver-containing activated carbon fibers (ACF) to understand the effects of different silver concentrations (tested various ACF containing 1, 5, 10, and $20 \mathrm{mg}$ 
per $100 \mathrm{~cm}^{2}$ of silver) on the efficiency of a silver-containing dressing. The obtained results indicated that various silvercontaining activated carbon fibers exhibited good antibacterial effects against $P$. aeruginosa and biocompatibility in terms of cell viability. Silver concentration showed a minor influence on cell growth. In vivo results achieved in rat infected excision wound model suggest that various produced Ag-ACF can promote infected wound healing in early phase compared to other commercial silver-containing dressings and promoting granulation and collagen deposition.

Archana et al. [62] created wound healing material with chitosan, polyvinylpyrrolidone (PVP), and silver oxide nanoparticles $\left(\mathrm{Ag}_{2} \mathrm{O}\right)$ (CPS films) and were characterized in vitro and in vivo. In vitro results show that the antibacterial activity of CPS against E. coli and S. aureus was measured by disc diffusion method. The impregnated chitosan-PVP solution showed stronger inhibitory effect against $S$. aureus than E. coli. CPS films were also tested in vivo, in rats' wound healing study (within 14 days). On the 14th day, wounds treated with CPS were healed almost completely (99\%), whereas in gauze and chitosan groups wound closure rates were $95 \%$ and $91 \%$, respectively. In conclusion, wounds treated with CPS healed faster than chitosan treated groups and gauze dressing.

Anisha et al. [63] develop an antimicrobial sponge composed of chitosan, hyaluronic acid (HA), and nanosilver (nAg) as a wound dressing for diabetic foot ulcers (DFU) infected with drug resistant bacteria. Antibacterial properties were tested against $E$. coli, $S$. aureus, methicillin-resistant $S$. aureus (MRSA), P. aeruginosa, and K. pneumonia. Also sponge containing higher concentrations of $\mathrm{nAg}(0.005 \%$, $0.01 \%$, and $0.02 \%$ ) showed antibacterial activity against MRSA. They also tested toxicity of aAg on fibroblast cells and notice that toxicity depends of the concentration of $\mathrm{nAg}$. The obtained results show that sponge could be used as a potential material for wound dressing for DFU infected with antibioticresistant bacteria.

Mi et al. [64] prepared a new type of a bilayer chitosan wound dressing with sustainable delivery of silver sulfadiazine (AgNP) was examined in vitro and in vivo (infected wounds in rats). In vitro test showed that chitosan disc inhibited growth of $P$. aeruginosa more effectively than S. aureus. In vivo antimicrobial assay showed that AgSD chitosan wound dressing limited growth of both bacterial strains. Importantly, this dressing was characterized by an excellent oxygen permeability, which controls the water vapor transmission rate and promotes water uptake capability.

Ahamed et al. [65] examined composites containing regenerated cellulose (RC) and chitosan (Ch) impregnated with AgNP with and without gentamicin $(G)$ in experimental wounds of rats. This group tested wound healing rate in wound covered by soframycin, RC-Ch-Ag, and RC-Ch-AgG. Control wound was covered with sterile cotton gauze dipped with gentamicin. This study revealed that wound treated with RC-Ch-Ag and RC-Ch-Ag-G composite shows statistically significant difference in healing rate (resp., 96\% of contraction and completely contracted) to untreated control (74\% of wound contraction).
Guthrie and colleague [66] examined commercially available dressings: Inadine, Acticoat, and Activon Tulle in rabbit model of contaminated (by $S$. aureus) forelimb muscle injury. A positive control group was treated with antibiotics. This study demonstrated that Inadine and Acticoat significantly reduced the tissue bacterial load compared to saline-soaked gauze dressing. Application on presented model of Activon Tulle occurred to have minimal antibacterial effect. It has been suggested that the use of these dressings could be considered as an adjunct to surgical debridement and systemic antibiotics for the treatment of contaminated injured tissue.

Also Boonkaew et al. [67] compared antimicrobial efficacy of two commercially available silver dressings (Acticoat, PolyMem SilverW) with silver hydrogel dressing in burn wound. Antimicrobial properties were tested on burn wound pathogens: P. aeruginosa, S. aureus (MSSA), A. baumannii, C. albicans, S. aureus (MRSA), and E. faecalis (VRE). The inhibition length zone of Acticoat in disc diffusion method ranged from 13.9 to $18.4 \mathrm{~mm}$ for all microbes. Similar results were obtained for silver hydrogel and one-year silver hydrogel, (9.0-11.8 mm), except MRSA. It seems likely to inhibit the growth of bacteria directly underneath the examined wound dressing. PolyMem SilverW had a minimal zone of inhibition only for MSSA $(10 \mathrm{~mm})$ and C. albicans $(9.8 \pm$ $0.5 \mathrm{~mm}$ ). The results obtained from broth culture and the Live/Dead Baclight ${ }^{\mathrm{TM}}$ methods show that Acticoat had the most effective antimicrobial properties. In conclusion, silver hydrogel reduced growth of the most tested microorganism and can be used as a wound dressing.

Velázquez-Velázquez and coworkers [68] in presented study evaluated the antibiofilm activities of AgNP impregnated in commercial dressings against $P$. aeruginosa. These bacteria were isolated of chronic wounds from a hospital patient with diabetes type II and DFU. Two Gram-negative bacteria were identified as $P$. aeruginosa and K. pneumoniae and two Gram-positive bacteria were identified as $S$. epidermidis and E. faecalis. The antimicrobial activity of AgNP was tested within biofilms generated under slow fluid shear conditions. Outcomes obtained by this group suggest that the use of dressings with AgNP may either prevent or reduce microbial growth in the wound microenvironment. Moreover reducing wound bioburden may improve wound healing outcomes.

Siegel et al. [69] tested silver-negative pressure dressing used in conjunction with a wound vacuum-assisted closure (VAC) technology in massive soft tissue lose (involving the pelvis and extremities from trauma, infections, and tumors remains). They examined 42 patients with massive tissue lose $>200 \mathrm{~cm}^{2}$ (26 treated with the wound VAC alone and 16 patients treated with the silver dressing). The obtained results show that average hospitalization time for patient from VCA group was 33 days and 14.3 days in the VAC with silver dressing group. In group treated with silver the number of types of operative debridement was almost twice less than in VCA group. They applied negative pressure dressing in combination with the wound VAC as part of routine care of patients with massive wounds of the pelvis and extremities. 
4.6. Toxicity and Applications of Silver and Silver Nanoparticle Dressings. Most studies suggest that silver nanoparticles are nontoxic. However, toxicity from silver is observed in the form of argyria. This is caused by silver ions release from the dressing in large open wounds [69].

Also, several studies have shown that silver nanoparticles can induce a toxic response in different mammalian cell lines [70-73]. Additionally, silver treatments used in burn care have been reported to be toxic to human cells: keratinocytes $(\mathrm{HaCaT})$ or human diabetic fibroblasts $[74,75]$. Sambale et al. tested silver nanoparticles for their toxic effect on fibroblasts (NIH-3T3), on a human lung adenocarcinoma epithelial cell line (A-549), on PC-12-cells, rat adrenal pheochromocytoma cell line, and HEP-G2-cells, and on human hepatocellular carcinoma cell line. Calculated $\mathrm{IC}_{50}$ (Inhibitory Concentration), TLC (Total Lethal Concentration), and NOAEC ("No Observable Adverse Effect Concentration") values were different for each cell line ranging from $3 \mathrm{ppm}$ to $144 \mathrm{ppm}$. The cells that give the most toxic response to silver nanoparticles were PC-12 and NIH-3T3 cells ( $\mathrm{IC}_{50}$ low as $4 \mathrm{ppm}$ ), whereas the $\mathrm{IC}_{50}$ for the A-549 cells was about $10 \mathrm{ppm}$ [76].

On the other hand, Pérez-Díaz et al. [77] evaluated the antibiofilm effect of chitosan gel formulations loaded with AgNP versus silver sulfadiazine (SSD) which is currently being used in a clinic, on isolated bacterial strains. They also tested cytotoxic effect on human primary fibroblasts. Results obtained by this group show that chitosan gels with AgNP have lover toxicity on human fibroblast than SSD.

Few in vivo studies have been performed to evaluate the toxic mode of action of nanosilver and oxidative stress as an important mechanism for nanosilver toxicity. Tiwari et al. [78] tested the various concentrations of silver nanoparticles (AgNP) to establish optimal dose for medicinal treatment. The used doses $(4,10,20$, and $40 \mathrm{mg} / \mathrm{kg})$ of silver nanoparticles were injected intravenously into the rats' tail. The results indicate that doses below $10 \mathrm{mg} / \mathrm{kg}$ were more least toxic showing no side effects, suggesting optimal dose for biomedical applications. Higher doses above $20 \mathrm{mg} / \mathrm{kg}$ were shown to be toxic.

There are commercially available dressings that contain different concentrations of silver (Acticoat $0.84-1.34 \mathrm{mg}$ / $\mathrm{cm}^{2}$ ) or silver nanoparticles (PolyMem Silver minimum $0.124 \mathrm{mg} / \mathrm{cm}^{2}$ ). Product information indicates that Algicell Ag dressing contains $1.4 \%$ ionic silver [79, 80]. Amount of silver released varies from below $10 \mathrm{mg} / 100 \mathrm{~cm}^{2}$ to over $100 \mathrm{mg} / \mathrm{cm}^{2}$ but they prove that the concentration more than $10-40 \mathrm{ppm}$ is necessary for antimicrobial activity $[81,82]$.

Burd et al. [83] studied the cytotoxicity of five commercially available wound dressings: Acticoat, Aquacel Ag, Contreet $^{\circ}$ Foam, PolyMem ${ }^{\circ}$ Silver, and Urgotul ${ }^{\circ}$ SSD. The study confirmed that the cytotoxicity was dependent on the dressing and on the concentration of silver in the pretreatment solution. The cytotoxicity in various cultures such as monolayer cell culture, tissue explant culture model, and mouse expurgated wound model was studied. The results showed that Acticoat, Aquacel Ag, and Contreet Foam presented the most significant cytotoxic effects in keratinocyte and fibroblast cultures. In the tissue explant culture model, in which the epidermal cell proliferation was evaluated, all silver dressings cause significant delay of reepithelialization. In the mouse excisional wound model, Acticoat and Contreet Foam indicated a strong inhibition of wound reepithelialization on day 7 after wounding.

Caution should be taken in using silver-based dressings. Depending on the product, the dressing should be changed after 1-7 days [84]. Silver dressings can be used in pediatric cases. Nevertheless, they should be applied with caution and should not be used for more than two weeks without good clinical reason [85].

\section{Future Perspective}

Nowadays, silver and silver nanoparticles (AgNP) are used in a wide range of healthcare, food industry, and domiciliary applications and are commonly found in different type of materials and textiles. Applications of silver and silver nanoparticles have a lot of positive aspects: it is added to wound dressings, medical supplements, catheters, and implants to inhibit the growth of pathogens and biofilm production. Also nanosilver has been used in medical textiles: bedclothes, towels, and clothes, to eliminate the pathogenic microbes in a clinical environment. Furthermore silver nanoparticles are added to cosmetics as antiseptic and preservative agents.

The point is that overuse and ignorance about behavior of AgNP in production, consumption, and utilization may consequently cause damage in the environment (especially to human and animal health). One of the negative aspects of overuse of silver derivatives is the fact that AgNP accumulate in skin (causing argyria), kidney, brain, and heart. Commonly used drugs are becoming less effective in combating pathogenic microorganisms encountered in a hospital. In the future we think that medicaments based on silver will become widespread weapon in the fight against opportunistic bacterial strains.

\section{Conclusion}

The medical use of silver is not a new approach. Silver and silver derivatives have been employed as an antimicrobial for century. Year by year the application of silver has been increasing in medical practice. In the past, silver in form of metallic or silver nitrate was used to treat skin infection, chronic wounds and as a component of novel wound dressing. Silver in ionized form or nanoparticles exhibits excellent antimicrobial, antifungal properties and is used for coating medical devices for preventing biofilm formation by pathogenic bacteria. Antimicrobial properties of silver have been used in preparation of wound dressing. This type of wound dressings is widely used in clinical practice and shows promising results in healing of contaminated wounds.

\section{Conflict of Interests}

The authors declare that there is no conflict of interests regarding the publication of this paper. 


\section{Acknowledgments}

This work was supported by the Polish National Science Center (NCN), 2011/01/B/ST5/07818, as well as Mazowian Peptide Cluster. The authors thank Artur Miecznikowski, M.D., for his suggestions and valuable guidance during writing this paper.

\section{References}

[1] L. S. Devi and S. R. Joshi, "Evaluation of the antimicrobial potency of silver nanoparticles biosynthesized by using an endophytic fungus, Cryptosporiopsis ericae PS4," Journal of Microbiology, vol. 52, no. 8, pp. 667-674, 2014.

[2] I. Sondi and B. Salopek-Sondi, "Silver nanoparticles as antimicrobial agent: a case study on E. coli as a model for Gramnegative bacteria," Journal of Colloid and Interface Science, vol. 275, no. 1, pp. 177-182, 2004.

[3] K. M. M. Abou El-Nour, A. Eftaiha, A. Al-Warthan, and R. A. A. Ammar, "Synthesis and applications of silver nanoparticles," Arabian Journal of Chemistry, vol. 3, no. 3, pp. 135-140, 2010.

[4] Y. Murali Mohan, K. Lee, T. Premkumar, and K. E. Geckeler, "Hydrogel networks as nanoreactors: a novel approach to silver nanoparticles for antibacterial applications," Polymer, vol. 48, no. 1, pp. 158-164, 2007.

[5] M. Ahamed, M. S. AlSalhi, and M. K. J. Siddiqui, "Silver nanoparticle applications and human health," Clinica Chimica Acta, vol. 411, no. 23-24, pp. 1841-1848, 2010.

[6] J. Fong, "The use of silver products in the management of burn wounds: change in practice for the burn unit at Royal Perth Hospital," Primary Intention: The Australian Journal of Wound Management, vol. 13, no. 4, pp. 16-22, 2005.

[7] J. J. Castellano, S. M. Shafii, F. Ko et al., "Comparative evaluation of silver-containing antimicrobial dressings and drugs," International Wound Journal, vol. 4, no. 2, pp. 114-122, 2007.

[8] X. Chen and H. J. Schluesener, "Nanosilver: a nanoproduct in medical application," Toxicology Letters, vol. 176, no. 1, pp. 1-12, 2008.

[9] F. R. Russell, W. B. Pathm, and A. D. Hugo, "Antimicrobial activity and action of silver," in Progress in Medicinal Chemistry, vol. 31, pp. 351-371, Elsevier, Amsterdam, The Netherlands, 1994.

[10] P. Uttayarat, J. Eamsiri, T. Tangthong, and P. Suwanmala, "Radiolytic synthesis of colloidal silver nanoparticles for antibacterial wound dressings," Advances in Materials Science and Engineering, vol. 2015, Article ID 376082, 6 pages, 2015.

[11] A. B. G. Lansdown, "Silver in health care: antimicrobial effects and safety in use," Current Problems in Dermatology, vol. 33, pp. 17-34, 2006.

[12] D. E. Marx and D. J. Barillo, "Silver in medicine: the basic science," Burns, vol. 40, supplement 1, pp. S9-S18, 2014.

[13] J. W. Alexander, "History of the medical use of silver," Surgical Infections, vol. 10, no. 3, pp. 289-292, 2009.

[14] J. Fong and F. Wood, "Nanocrystalline silver dressings in wound management: a review," International Journal of Nanomedicine, vol. 1, no. 4, pp. 441-449, 2006.

[15] S. Silver, L. T. Phung, and G. Silver, "Silver as biocides in burn and wound dressings and bacterial resistance to silver compounds," Journal of Industrial Microbiology and Biotechnology, vol. 33, no. 7, pp. 627-634, 2006.

[16] H. J. Klasen, "Historical review of the use of silver in the treatment of burns. I. Early uses," Burns, vol. 26, no. 2, pp. 117$130,2000$.
[17] D. J. Barillo and D. E. Marx, "Silver in medicine: a brief history BC 335 to present," Burns, vol. 40, supplement 1, pp. S3-S8, 2014.

[18] A. L. Roe, "Collosol argentum and its ophthalmic uses," British Medical Journal, vol. 1, article 104, 1915.

[19] R. Bandyopadhyaya, M. V. Sivaiah, and P. A. Shankar, "Silver-embedded granular activated carbon as an antibacterial medium for water purification," Journal of Chemical Technology and Biotechnology, vol. 83, no. 8, pp. 1177-1180, 2008.

[20] P. Jain and T. Pradeep, "Potential of silver nanoparticle-coated polyurethane foam as an antibacterial water filter," Biotechnology and Bioengineering, vol. 90, no. 1, pp. 59-63, 2005.

[21] V. A. Oyanedel-Craver and J. A. Smith, "Sustainable colloidalsilver-impregnated ceramic filter for point-of-use water treatment," Environmental Science \& Technology, vol. 42, no. 3, pp. 927-933, 2008.

[22] D. J. Barillo, M. Pozza, and M. Margaret-Brandt, "A literature review of the military uses of silver-nylon dressings with emphasis on wartime operations," Burns, vol. 40, no. 1, pp. S24S29, 2014.

[23] E. C. Abboud, J. C. Settle, T. B. Legare, J. E. Marcet, D. J. Barillo, and J. E. Sanchez, "Silver-based dressings for the reduction of surgical site infection: review of current experience and recommendation for future studies," Burns, vol. 40, no. 1, pp. S30-S39, 2014.

[24] M. N. Bates, "Mercury amalgam dental fillings: an epidemiologic assessment," International Journal of Hygiene and Environmental Health, vol. 209, no. 4, pp. 309-316, 2006.

[25] Y. Xu, C. W. Gao, X. H. Li et al., "In vitro antifungal activity of silver nanoparticles against ocular pathogenic filamentous fungi," Journal of Ocular Pharmacology and Therapeutics, vol. 29, no. 2, pp. 270-274, 2013.

[26] K. Dunn and V. Edwards-Jones, "The role of Acticoat" with nanocrystalline silver in the management of burns," Burns, vol. 30, supplement 1, pp. S1-S9, 2004.

[27] M. Ip, S. L. Lui, V. K. M. Poon, I. Lung, and A. Burd, "Antimicrobial activities of silver dressings: an in vitro comparison," Journal of Medical Microbiology, vol. 55, no. 1, pp. 59-63, 2006.

[28] D. J. Leaper, "Silver dressings: their role in wound management," International Wound Journal, vol. 3, no. 4, pp. 282-294, 2006.

[29] J. B. Wright, K. Lam, and R. E. Burrell, "Wound management in an era of increasing bacterial antibiotic resistance: a role for topical silver treatment," American Journal of Infection Control, vol. 26, no. 6, pp. 572-577, 1998.

[30] Q. L. Feng, J. Wu, G. Q. Chen, F. Z. Cui, T. N. Kim, and J. O. Kim, "A mechanistic study of the antibacterial effect of silver ions on Escherichia coli and Staphylococcus aureus," Journal of Biomedical Materials Research, vol. 52, no. 4, pp. 662-668, 2000.

[31] K. Madhumathi, P. T. Sudheesh Kumar, S. Abhilash et al., "Development of novel chitin/nanosilver composite scaffolds for wound dressing applications," The Journal of Materials Science: Materials in Medicine, vol. 21, no. 2, pp. 807-813, 2010.

[32] U. Samuel and J. P. Guggenbichler, "Prevention of catheterrelated infections: the potential of a new nano-silver impregnated catheter," International Journal of Antimicrobial Agents, vol. 23, supplement 1, pp. 75-78, 2004.

[33] K. Mijnendonckx, N. Leys, J. Mahillon, S. Silver, and R. Van Houdt, "Antimicrobial silver: uses, toxicity and potential for resistance," BioMetals, vol. 26, no. 4, pp. 609-621, 2013.

[34] J. R. Morones, J. L. Elechiguerra, A. Camacho et al., "The bactericidal effect of silver nanoparticles," Nanotechnology, vol. 16, no. 10, pp. 2346-2353, 2005. 
[35] P.-O. Rujitanaroj, N. Pimpha, and P. Supaphol, "Wounddressing materials with antibacterial activity from electrospun gelatin fiber mats containing silver nanoparticles," Polymer, vol. 49, no. 21, pp. 4723-4732, 2008.

[36] A. Panáček, L. Kvítek, R. Prucek et al., "Silver colloid nanoparticles: synthesis, characterization, and their antibacterial activity," The Journal of Physical Chemistry B, vol. 110, no. 33, pp. 16248$16253,2006$.

[37] C. L. Fox Jr. and S. M. Modak, "Mechanism of silver sulfadiazine action on burn wound infections," Antimicrobial Agents and Chemotherapy, vol. 5, no. 6, pp. 582-588, 1974.

[38] S. Opasanon, P. Muangman, and N. Namviriyachote, "Clinical effectiveness of alginate silver dressing in outpatient management of partial-thickness burns," International Wound Journal, vol. 7, no. 6, pp. 467-471, 2010.

[39] P. Muangman, C. Pundee, S. Opasanon, and S. Muangman, "A prospective, randomized trial of silver containing hydrofiber dressing versus $1 \%$ silver sulfadiazine for the treatment of partial thickness burns," International Wound Journal, vol. 7, no. 4, pp. 271-276, 2010.

[40] A. Mabrouk, N. S. Boughdadi, H. A. Helal, B. M. Zaki, and A. Maher, "Moist occlusive dressing (Aquacel Ag) versus moist open dressing $\left(\mathrm{MEBO}^{\circ}\right)$ in the management of partial-thickness facial burns: a comparative study in Ain Shams University," Burns, vol. 38, no. 3, pp. 396-403, 2012.

[41] J. S. Kim, E. Kuk, K. N. Yu et al., "Antimicrobial effects of silver nanoparticles," Nanomedicine: Nanotechnology, Biology and Medicine, vol. 3, no. 1, pp. 95-101, 2007.

[42] S. Shrivastava, T. Bera, A. Roy, G. Singh, P. Ramachandrarao, and D. Dash, "Characterization of enhanced antibacterial effects of novel silver nanoparticles," Nanotechnology, vol. 18, no. 22, pp. 22510-22513, 2007.

[43] S. Le Page, D. Raoult, and J.-M. Rolain, "Real-time video imaging as a new and rapid tool for antibiotic susceptibility testing by the disc diffusion method: a paradigm for evaluating resistance to imipenem and identifying extended-spectrum $\beta$ lactamases," International Journal of Antimicrobial Agents, vol. 45, no. 1, pp. 61-65, 2015.

[44] J. Hudzicki, "Kirby-Bauer Disk Diffusion Susceptibility Test Protocol 2013," http://www.microbelibrary.org/component/resource/laboratory-test/3189-kirby-bauer-disk-diffusion-susceptibility-test-protocol.

[45] A. R. Shahverdi, A. Fakhimi, H. R. Shahverdi, and S. Minaian, "Synthesis and effect of silver nanoparticles on the antibacterial activity of different antibiotics against Staphylococcus aureus and Escherichia coli," Nanomedicine: Nanotechnology, Biology, and Medicine, vol. 3, no. 2, pp. 168-171, 2007.

[46] S. Rajawat and M. S. Qureshi, "Comparative study on bactericidal effect of silver nanoparticles, synthesized using green technology, in combination with antibiotics on Salmonella typhi," Journal of Biomaterials and Nanobiotechnology, vol. 3, no. 4, pp. 480-485, 2012.

[47] A. M. Fayaz, K. Balaji, M. Girilal, R. Yadav, P. T. Kalaichelvan, and R. Venketesan, "Biogenic synthesis of silver nanoparticles and their synergistic effect with antibiotics: a study against gram-positive and gram-negative bacteria," Nanomedicine: Nanotechnology, Biology, and Medicine, vol. 6, no. 1, pp. e103e109, 2010.

[48] R. Thomas, A. P. Nair, S. Kr, J. Mathew, and R. Ek, "Antibacterial activity and synergistic effect of biosynthesized AgNPs with antibiotics against multidrug-resistant biofilm-forming coagulase-negative staphylococci isolated from clinical samples," Applied Biochemistry and Biotechnology, vol. 173, no. 2, pp. 449-460, 2014.

[49] S. Z. H. Naqvi, U. Kiran, M. I. Ali et al., "Combined efficacy of biologically synthesized silver nanoparticles and different antibiotics against multidrug-resistant bacteria," International Journal of Nanomedicine, vol. 8, pp. 3187-3195, 2013.

[50] K. N. J. Stevens, O. Crespo-Biel, E. E. M. Van den Bosch et al., "The relationship between the antimicrobial effect of catheter coatings containing silver nanoparticles and the coagulation of contacting blood," Biomaterials, vol. 30, no. 22, pp. 3682-3690, 2009.

[51] D. Roe, B. Karandikar, N. Bonn-Savage, B. Gibbins, and J.B. Roullet, "Antimicrobial surface functionalization of plastic catheters by silver nanoparticles," Journal of Antimicrobial Chemotherapy, vol. 61, no. 4, pp. 869-876, 2008.

[52] M. D. Khare, S. S. Bukhari, A. Swann, P. Spiers, I. McLaren, and J. Myers, "Reduction of catheter-related colonisation by the use of a silver zeolite-impregnated central vascular catheter in adult critical care," Journal of Infection, vol. 54, no. 2, pp. 146150, 2007.

[53] K. N. J. Stevens, S. Croes, R. S. Boersma et al., "Hydrophilic surface coatings with embedded biocidal silver nanoparticles and sodium heparin for central venous catheters," Biomaterials, vol. 32, no. 5, pp. 1264-1269, 2011.

[54] H. Akiyama and S. Okamoto, "Prophylaxis of indwelling urethral catheter infection: clinical experience with a modified Foley catheter and drainage system," The Journal of Urology, vol. 121, no. 1, pp. 40-42, 1979.

[55] T. B. Karchmer, E. T. Giannetta, C. A. Muto, B. A. Strain, and B. M. Farr, "A randomized crossover study of silver-coated urinary catheters in hospitalized patients," Archives of Internal Medicine, vol. 160, no. 21, pp. 3294-3298, 2000.

[56] J. S. Boateng, K. H. Matthews, H. N. E. Stevens, and G. M. Eccleston, "Wound healing dressings and drug delivery systems: a review," Journal of Pharmaceutical Sciences, vol. 97, no. 8, pp. 2892-2923, 2008.

[57] T. D. Turner, "Interactive dressings used in the management of human soft tissue injuries and their potential in veterinary practice," Veterinary Dermatology, vol. 8, no. 4, pp. 235-242, 1997.

[58] L. Jeong, M. H. Kim, J. Jung, B. M. Min, and W. H. Park, "Effect of silk fibroin nanofibers containing silver sulfadiazine on wound healing," International Journal of Nanomedicine, vol. 9, pp. 5277-5287, 2014.

[59] P. J. Finley, R. E. Huckfeldt, K. D. Walker, and L. P. Shornick, "Silver dressings improve diabetic wound healing without reducing bioburden," Wounds-A Compendium of Clinical Research and Practice, vol. 25, no. 10, pp. 293-301, 2013.

[60] Y. H. Lin, W. S. Hsu, W. Y. Chung, T. H. Ko, and J. H. Lin, "Silverbased wound dressings reduce bacterial burden and promote wound healing," International Wound Journal, 2015.

[61] Y.-H. Lin, W.-S. Hsu, W.-Y. Chung, T.-H. Ko, and J.-H. Lin, "Evaluation of various silver-containing dressing on infected excision wound healing study," Journal of Materials Science: Materials in Medicine, vol. 25, no. 5, pp. 1375-1386, 2014.

[62] D. Archana, B. K. Singh, J. Dutta, and P. K. Dutta, "ChitosanPVP-nano silver oxide wound dressing: in vitro and in vivo evaluation," International Journal of Biological Macromolecules, vol. 73, pp. 49-57, 2015.

[63] B. S. Anisha, R. Biswas, K. P. Chennazhi, and R. Jayakumar, "Chitosan-hyaluronic acid/nano silver composite sponges for 
drug resistant bacteria infected diabetic wounds," International Journal of Biological Macromolecules, vol. 62, pp. 310-320, 2013.

[64] F.-L. Mi, Y.-B. Wu, S.-S. Shyu et al., "Control of wound infections using a bilayer chitosan wound dressing with sustainable antibiotic delivery," Journal of Biomedical Materials Research, vol. 59, no. 3, pp. 438-449, 2002.

[65] M. I. N. Ahamed, S. Sankar, P. M. Kashif, S. K. H. Basha, and T. P. Sastry, "Evaluation of biomaterial containing regenerated cellulose and chitosan incorporated with silver nanoparticles," International Journal of Biological Macromolecules, vol. 72, pp. 680-686, 2015.

[66] H. C. Guthrie, K. R. Martin, C. Taylor et al., "A pre-clinical evaluation of silver, iodine and Manuka honey based dressings in a model of traumatic extremity wounds contaminated with Staphylococcus aureus," Injury, vol. 45, no. 8, pp. 1171-1178, 2014.

[67] B. Boonkaew, M. Kempf, R. Kimble, P. Supaphol, and L. Cuttle, "Antimicrobial efficacy of a novel silver hydrogel dressing compared to two common silver burn wound dressings: Acticoat and PolyMem Silver", Burns, vol. 40, no. 1, pp. 89-96, 2014.

[68] J. L. Velázquez-Velázquez, A. Santos-Flores, J. Araujo-Meléndez et al., "Anti-biofilm and cytotoxicity activity of impregnated dressings with silver nanoparticles," Materials Science and Engineering C, vol. 49, pp. 604-611, 2015.

[69] H. J. Siegel, D. F. Herrera, and J. Gay, "Silver negative pressure dressing with vacuum-assisted closure of massive pelvic and extremity wounds," Clinical Orthopaedics and Related Research, vol. 472, no. 3, pp. 830-835, 2014.

[70] A. Wadhera and M. Fung, "Systemic argyria associated with ingestion of colloidal silver," Dermatology Online Journal, vol.11, no. 1, article 12, 2005, http://escholarship.org/uc/item/0832g6d3.

[71] P. Chairuangkitti, S. Lawanprasert, S. Roytrakul et al., "Silver nanoparticles induce toxicity in A549 cells via ROS-dependent and ROS-independent pathways," Toxicology in Vitro, vol. 27, no. 1, pp. 330-338, 2013.

[72] L. Braydich-Stolle, S. Hussain, J. J. Schlager, and M.-C. Hofmann, "In vitro cytotoxicity of nanoparticles in mammalian germline stem cells," Toxicological Sciences, vol. 88, no. 2, pp. 412-419, 2005.

[73] S. M. Hussain, K. L. Hess, J. M. Gearhart, K. T. Geiss, and J. J. Schlager, "In vitro toxicity of nanoparticles in BRL 3A rat liver cells," Toxicology in Vitro, vol. 19, no. 7, pp. 975-983, 2005.

[74] M. Kempf, R. M. Kimble, and L. Cuttle, "Cytotoxicity testing of burn wound dressings, ointments and creams: a method using polycarbonate cell culture inserts on a cell culture system," Burns, vol. 37, no. 6, pp. 994-1000, 2011.

[75] S.-B. Zou, W.-Y. Yoon, S.-K. Han, S.-H. Jeong, Z.-J. Cui, and W.K. Kim, "Cytotoxicity of silver dressings on diabetic fibroblasts," International Wound Journal, vol. 10, no. 3, pp. 306-312, 2013.

[76] F. Sambale, S. Wagner, F. Stahl, R. R. Khaydarov, T. Scheper, and D. Bahnemann, "Investigations of the toxic effect of silver nanoparticles on mammalian cell lines," Journal of Nanomaterials, vol. 2015, Article ID 136765, 9 pages, 2015.

[77] M. Pérez-Díaz, E. Alvarado-Gomez, M. Magaña-Aquino et al., "Anti-biofilm activity of chitosan gels formulated with silver nanoparticles and their cytotoxic effect on human fibroblasts," Materials Science and Engineering: C, vol. 60, pp. 317-323, 2016.

[78] D. K. Tiwari, T. Jin, and J. Behari, "Dose-dependent invivo toxicity assessment of silver nanoparticle in Wistar rats," Toxicology Mechanisms and Methods, vol. 21, no. 1, pp. 13-24, 2011.
[79] A. B. G. Lansdown and A. Williams, "How safe is silver in wound care?" Journal of Wound Care, vol. 13, no. 4, pp. 131-136, 2004.

[80] B. Boonkaew, M. Kempf, R. Kimble, P. Supaphol, and L. Cuttle, "Antimicrobial efficacy of a novel silver hydrogel dressing compared to two common silver burn wound dressings: Acticoat and PolyMem Silver"," Burns, vol. 40, no. 1, pp. 89-96, 2014.

[81] A. B. G. Lansdown, "Silver in health care: antimicrobial effects and safety in use," Current Problems in Dermatology, vol. 33, pp. 17-34, 2006.

[82] M. H. Cavanagh, R. E. Burrell, and P. L. Nadworny, "Evaluating antimicrobial efficacy of new commercially available silver dressings," International Wound Journal, vol. 7, no. 5, pp. 394405, 2010.

[83] A. Burd, C. H. Kwok, S. C. Hung et al., "A comparative study of the cytotoxicity of silver-based dressings in monolayer cell, tissue explant, and animal models," Wound Repair and Regeneration, vol. 15, no. 1, pp. 94-104, 2007.

[84] J. Dissemond, M. Augustin, S. A. Eming et al., "Modern wound care-practical aspects of non-interventional topical treatment of patients with chronic wounds," Journal of the German Society of Dermatology, vol. 12, no. 7, pp. 541-555, 2014.

[85] R. J. White, S. Fumarola, and J. Denyer, "Interim advice on silver dressings in paediatric wound and skin care," British Journal of Nursing, vol. 20, supplement S11, 2011. 

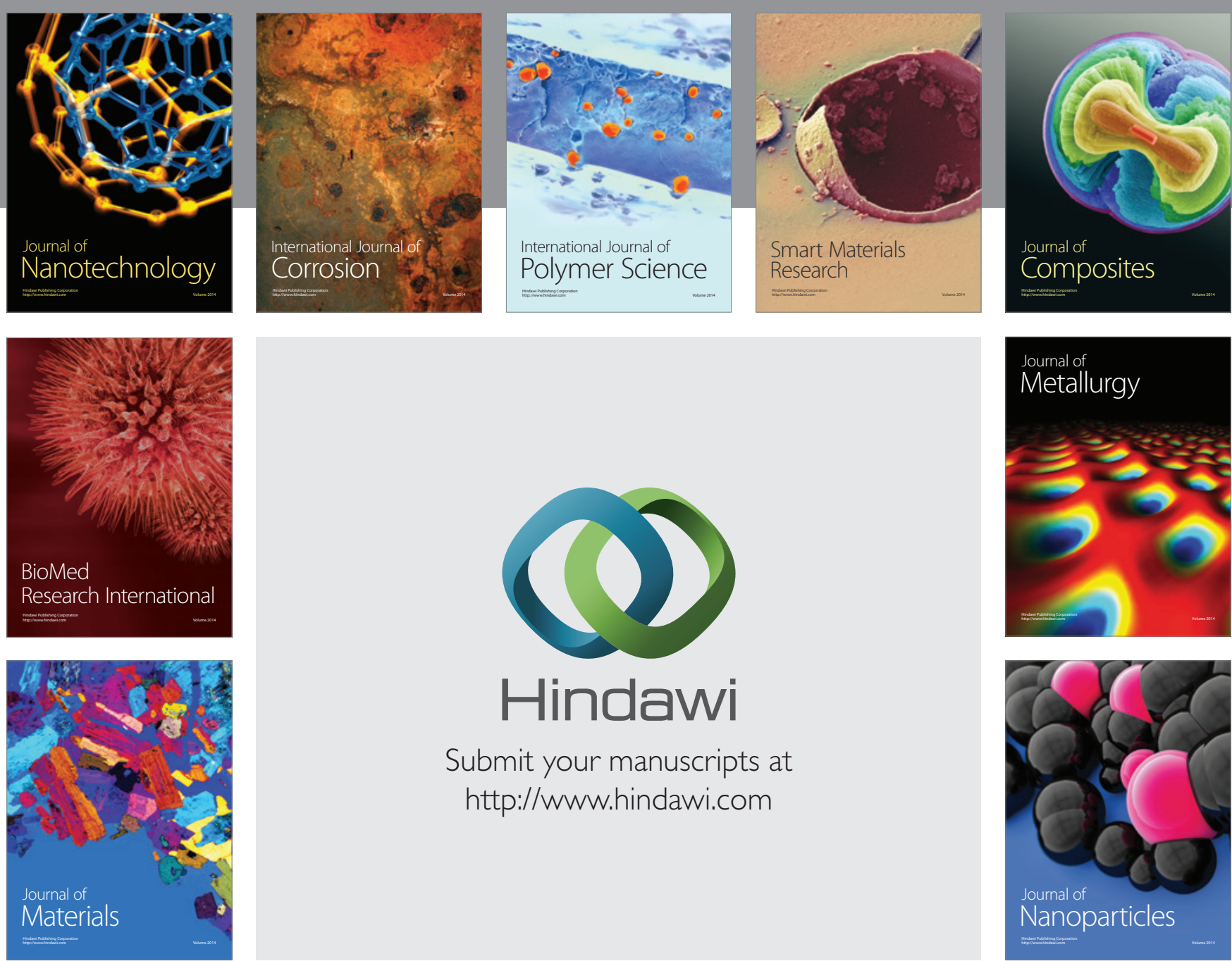

\section{Hindawi}

Submit your manuscripts at

http://www.hindawi.com

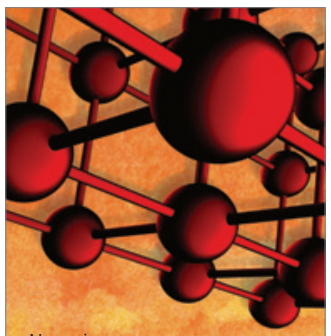

Materials Science and Engineering
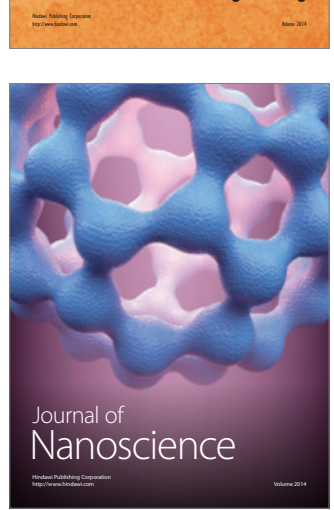
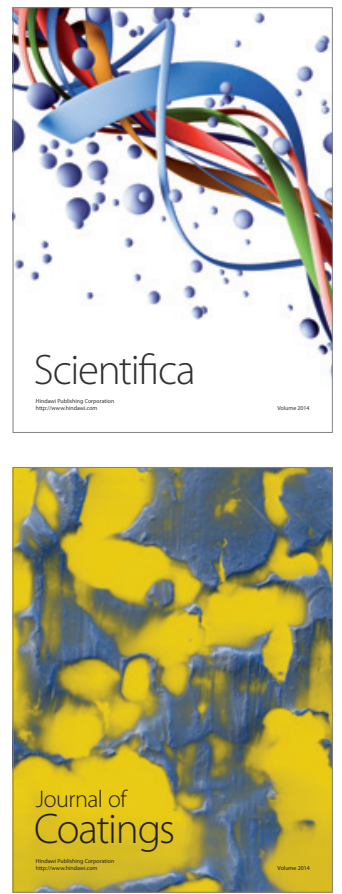
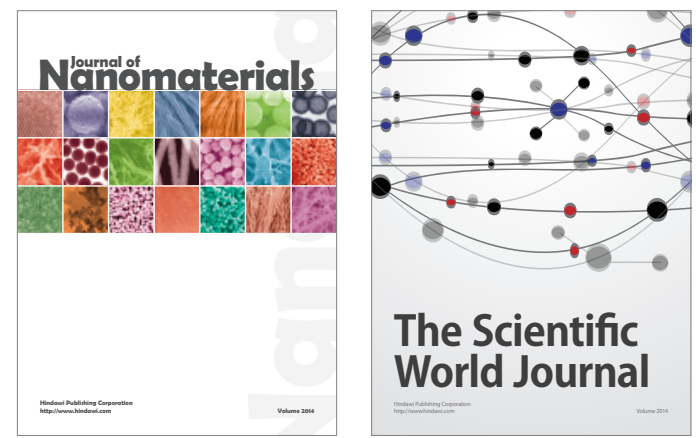

The Scientific World Journal
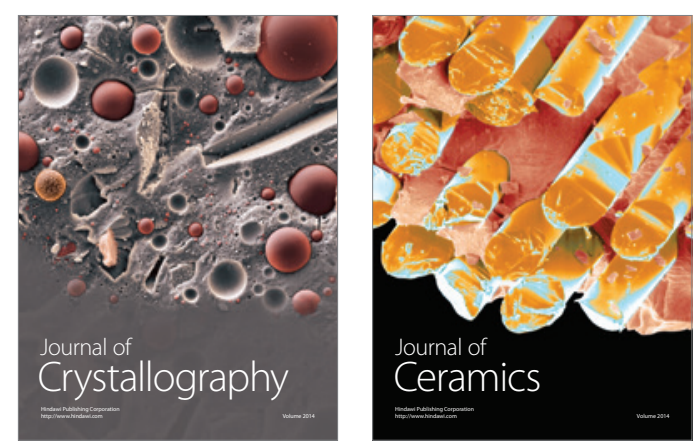
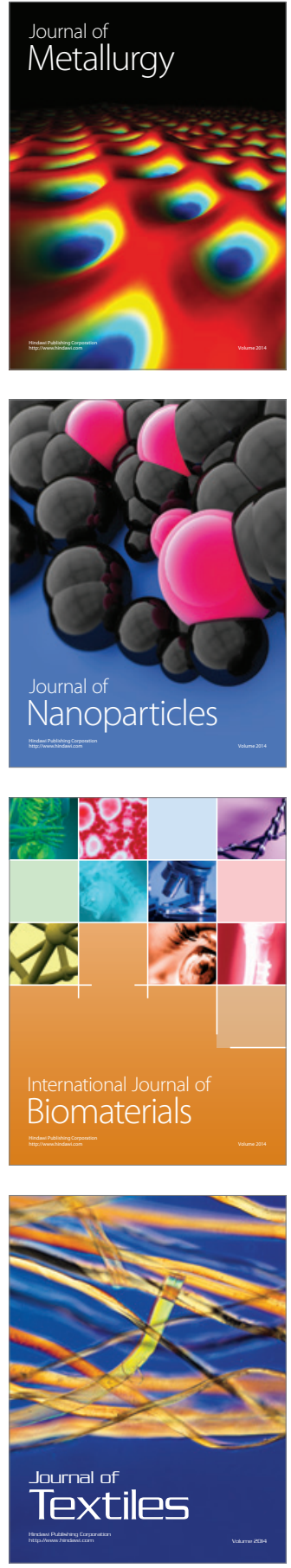